This additional equation, combined with other equations already known, gives all the information required. We deduce, for example, that the number of electrons in the universe is $1.29 \times 10^{79}$; and that the original radius of the universe, before it started to expand, was 1070 million light-years. Most important of all, we find that the consequent rate of expansion of the universe is $528 \mathrm{~km}$. per sec. per megaparsec distance. The observational determinations from the recession of the spiral nebulæ (which might be a little lower, since they include any countervailing gravitational attraction) range from $430 \mathrm{~km}$. to $550 \mathrm{~km}$. per sec. per megaparsec. We can feel little doubt, therefore, that the observed motions of the nebulæ are genuine and represent the expansion effect predicted by relativity. We must reconcile ourselves to this alarming rate of expansion, which plays havoc with older ideas as to the time-scale.

However interesting may be the application of this theory to the universe, the application to the interior of the atom seems likely to be still more fruitful. Now that we know the magnitude of the radius of curvature, we can set aside the arbitrary metre and use this natural unit in our equations. The big uninformative coefficients disappear; and the equations are so much simplified that, I think, I have a fair idea of what they really mean and how they work. In particular, the relation of the proton to the electron is now apparent, and the theoretical ratio of their masses is found to be $1847 \cdot 6$; this is certainly very near to the observed value.

I do not want to stress too much the accuracy or finality of these fir t results. I cannot see how anything can possibly be wrong with them; but then one never does see these faults until some new circumstance arises or some ingenious person comes forward to show us how blind we have been. At least, a way of progress has been found. I think that some day, when electrons and protons have come to order, we shall look back and see that the key to the mystery was lying somewhere in intergalactic space and was picked up by astronomers who measured the velocities and distances of nebulæ ten million light-years away.

\title{
Goethe as Biologist
}

\section{By Prof. F. J. CoLs, F.R.S., University of Reading}

$\mathrm{T}$ HE celebration of the centenary of the death of Goethe, which occurred on March 22, 1832, has evoked a series of works dealing with the activities of that unique genius. Among them is a critical biography by Prof. J. G. Robertson, the eminent authority on the life and works of Goethe.* This treatise is outside the scope, but not indeed outside the interests, of a scientific journal such as NATURE, except for the fact that it includes an enlightening chapter on Goethe's contributions to science. As a matter of personal history Prof. Robertson can scarcely be expected to take other than a detached view of Goethe's scientific achievements, and it is therefore not surprising to find him stating that "we look to Goethe, not for scientific discovery, an activity with which many other minds were as able-and perhaps better able-to cope successfully, but to more precious discoveries in the realm of the spirit and the imagination. May we not thus cherish something of a grudge that his immersion in scientific pursuits took up so very large a share in his life?" Prof. Robertson, however, would be the first to admit that Goethe himself would have indignantly denounced such an attitude, which strikes at the root of one of his characteristic speculations as to the nature of creative art. To him the living organism was a work of art which only an artist could be expected to comprehend. Further, it is precisely those attributes of the spirit and imagination which give to his scientific work the qualities we all find so fascinating.

It was in an essay written in 1795 , but not published until 1820, that Goethe focused attention on the unity of plan or organic constant which was

* "The lite and Work of Goethe, 1749-1832." By Prof. J. G. Robertson. Pp. xii $+350+-8$ plates. (London: George Routledge and Sons, Ltd., 1932.) 12s. 6il. net. supposed to underlie the organisation of all living beings. Since there was only one plan or idea, the world was regarded as something akin to a vast musical symposium, in which the poverty of a solitary theme was enriched by an endless and expanding series of variations. All forms were interpreted in terms of this ideal simulacrum, $\dagger$ and even man himself must be studied comparatively, working downwards from higher to lower types. This is the so-called law of reduction, or, to paraphrase the words of Geoffroy-there is but a single intangible being which becomes patent to our senses under diverse forms. Goethe was, of course, not the first to adopt such an attitude, but he was the first to convert it into an ordered scientific theory. The plan was put into operation or integrated by a controlling dynamic principle or Bildungstrieb. It is obvious at the outset that the theory is a scheme of development and not a principle of evolution, and, further, that its working out must depend on the institution of a system of homologies. There is one attractive feature in this point of view. However wrong it may be, it attempts to provide a common explanation of organic phenomena, and does not countenance the artificial separation of animals and plants.

Goethe's eager pursuit of homologies, of uniformity in diversity, was bound to lead to the conception that there was only one animal. Not merely was there a single animal type, but the integration of the type itself was effected by linking up into a series a number of similar, complete, subordinate entities like a string of beads. He extended the same speculation to plants, and interpreted, as others had done before him, the

+ Goethe would not have anproved this term, but the 'reality' of the idea is that of a mental abstraction projected on to paper like Owen's Archetype. 
leaves, sepals, petals, stamens, and pistils as variants of a common structure, just as the skull of the animal represented the efflorescence of the vertebral column. Leaf and vertebra were the elemental structures of animal and plant. He was not unmindful of the fact that modifications of the plan cannot be introduced without affecting the status of the whole, and his law of balance, that " in order to spend on one side, Nature is forced to economise on the other side", is closely related to the famous deduction made by Cuvier in 1812 of the law of correlation, which was exploited with such dramatic effect by himself and later comparative anatomists. Goethe was not the only biologist to become obsessed with this idealistic morphology. Even Johannes Müller himself embodied it in his "Inaugural Dissertation"-a lapse which this sensitive man lamented so deeply in later years that he bought up and destroyed all copies of the offending thesis.

It is not difficult to understand why Haeckel should have been led to credit Goethe with a share in the triumph of evolution, and to regard him as a forerunner of Darwin. Both Haeckel and Goethe were convinced upholders of the comparative method, and Haeckel was powerfully influenced by the genius of the poet. In Goethe's work on the metamorphosis of plants published in 1790 , which is considered to be the beginning of speculative morphology,* there are passages which give some support to the claim. Everything depends on his interpretation of what is called 'metamorphosis '. Is it an objective historical reality, as any principle of organic evolution is considered to be, or is it a philosophical conception expressing nothing more than the realisation of a generalised subjective plan or idea, which itself is not inconsistent with Nature philosophy and special creation? He hesitates between these alternatives, nor does it appear that they were ever sharply contrasted in his own mind, and he has no consistent views with regard to either. His contemporaries included him among the Nature philosophers, and Goethe, who did not hesitate to express the liveliest dissatisfaction when his scientific works were misunderstood, never thought it worth while to correct them. In his later writings, however, he appears at times to have a clearer perception of the evolutionary alternative, but again, at the close of his life, in 1830, he was supporting Geoffroy in his contest with Cuvier, which shows how far he was from comprehending the historical implications of evolution. There is no evidence that he ever specifically discussed the problem of species, regarding such speculations as "a useless occupation which we may well leave to those who are fond of busying themselves with insoluble problems " (Robertson).

The main point of contact between Goethe and Haeckel lies, however, in the fact that the evolutionist, like the Nature philosopher, also expects to find uniformity in diversity, but he only looks for it where it may reasonably be expected to

* Goethe introduced the term morphology in 1817 , but his definition of it is not retained in modern usage. exist, nor is he in any way constrained to mould the facts or stretch the argument in those cases where the quest has been unsuccessful. Failure must not only be expected but also accepted, since it does not affect the essential truth of the principle of evolution, but merely its mode of operation. Whilst, therefore, Goethe's methods were up to a point those approved by Haeckel and the evolutionists, he goes, and must go, considerably beyond the permitted limits of scientific induction. Having assumed the existence of a single animal type, it follows that, unless evidence for such a type be forthcoming, every species must be manipulated to conform to it. Such was the error of Goethe and his successors the Nature philosophers, and it must be held definitely to exclude them from the evolutionary circle, although Goethe himself was never guilty of the ludicrous extravagances of his disciples. In one cardinal respect, however, he was remarkably sound. He saw that purely morphological speculation was as dust and ashes in the mouth compared with the vision of the form and activities of an animal as a living organic whole. Or in other words, the complete organism only can give us understanding of its inner meaning or idea.

The attitude adopted by Goethe towards the question of animal relationships may be profitably explored by a comparison of his two researches on the intermaxillary bone and the vertebral theory of the skull. The former was written up in 1784 and bears the date of $1786(s i c), \dagger$ but it was not published until 1831, although an abstract without illustrations appeared in 1817. The latter paper was drafted and communicated to friends in 1790 , but was actually published in 1820 , this belated publication being responsible for the priority dispute with Oken. The alleged absence of the premaxilla in man was considered to separate him definitely from the apes - a conclusion which ignored the fact that if the bone is absent in man it is also wanting in the higher apes. Goethe sought to establish its presence in man by methods not dissimilar from those of the modern comparative anatomist. He examined its condition in a number of mammals, noted variations in its state of development and correlated them with feeding habits, investigated aberrant cases such as that of the elephant, and succeeded in finding the bone in some species in which it had not been described. Finally, by comparing human adult and fœtal skulls, he demonstrated its presence in man. $\ddagger \mathrm{He}$ thus established the importance of embryology in the intepretation of adult structure. His work, in fact, is an admirable essay in comparative anatomy.

The research on the skull, however, belongs to another category. It has no concern with experience, but is an exploitation of the Idea. Whether the skull is vertebral in nature or not, cannot be tested by observation. If, however, we concede the point, the skull may have been formed on the

$\dagger$ This date is usually but erroneously quoted as the date of publication.

$\ddagger$ The bone was not first discovered in man by Goethe. Vesalius and Fallopius saw indications of it in 1543 and 1561, and Vicq D'Azyr described it in the human fœtus in 1780-84. 
vertebral pattern as the result of the operation of a creative force working according to plan, or it may have been produced from modified vertebræ by a process of evolution. In either event, the investigator is confronted with an abstraction beyond the means of verification. It is otherwise with the case of the intermaxillary bone. Here the 'metamorphosis' may be tested and observed in all its stages, and an evolutionary conclusion becomes not only possible but almost inevitable. But how did Goethe regard these two problems? To him their implications and significance were identical, and the only inference he drew from both of them was a confirmation of his theory of the common plan or idea. To such an outlook, deduction and induction are indistinguishable. Had the history of the intermaxillary bone suggested to his mind any conception of genetic relationships, he would surely have said so. Goethe therefore was a forerunner of Darwin only in the sense that before the historical continuity of species could be established it was necessary to formulate a doctrine of homologies, and in this important work Goethe played a leading part.

Not until the end of his life did Goethe exercise any appreciable influence on the biological thought of the period. This was due partly to delays in publication, but particularly to the imaginative and romantic character of his work-a quality rarely grateful to the academic mind. At first his influence was almost wholly reactionary, but the eclipse of Nature philosophy purged his writings of their ephemeral content and made it possible to form a sound judgment of the residue, with results that have only become evident in modern times. That his biological work will always command the respect and admiration of scientific men is a conclusion to which all his critics would assent.

\section{Goethe's Reflections on Nature}

$\mathrm{W}$ E reproduce below the translation of Goethe's reflections on Nature by T. H. Huxley, which was published as an introductory article to the first number of NaTuRE, dated Nov. 4, 1869. As originally printed, a casual reader might easily conclude that this lyrical composition was the work of Huxley himself, and in a letter to Dohrn, written shortly afterwards, he says: "It astonishes the British Philistines not a little. When they began to read it they thought it was mine, and that I had suddenly gone mad." Darwin himself was stirred to admiration, and wrote to Hooker as follows: "Lord, what a rhapsody that was of Goethe, but how well translated; it seemed to me, as I told Huxley, as if written by the maddest English scholar. It is poetry, and can I say anything more severe?" Huxley added to his translation some comments upon Goethe's " wonderful rhapsody on Nature which has been a delight to me from my youth up "; and he referred to it in an article entitled "Past and Present", contributed by him to the first issue of our fifty-first volume, on Nov. 1, 1894. In a footnote to this article, Huxley said: "A better translation than mine and an interesting account of the very curious obscurity which hangs about the parentage of Die Natur are to be found in Mr. J. Bailey Saunders' recently, published 'Goethe's Aphorisms and Reflections '."

\section{Nature: Aphorisms by Goethe *}

NATURE! We are surrounded and embraced by her : powerless to separate ourselves from her, and powerless to penetrate beyond her.

Without asking, or warning, she snatches us up into her circling dance, and whirls us on until we are tired and drop from her arms.

She is ever shaping new forms : what is, has never yet been; what has been, comes not again. Everything is new, and yet nought but the old.

We live in her midst and know her not. She is incessantly speaking to us, but betrays not her secret. We constantly act upon her, and yet have no power over her.

* From Nature, Nov. 4, 1869.

No. 3255, VoL. 129]
The one thing she seems to aim at is Individuality ; yet she cares nothing for individuals. She is always building up and destroying; but her workshop is inaccessible.

Her life is in her children ; but where is the mother ? She is the only artist; working-up the most uniform material into utter opposites; arriving, without a trace of effort, at perfection, at the most exact precision, though always veiled under a certain softness.

Each of her works has an essence of its own; each of her phenomena a special characterisation : and yet their diversity is in unity.

She performs a play; we know not whether she sees it herself, and yet she acts for us, the lookers-on.

Incessant life, development, and movement are in her, but she advances not. She changes for ever and ever, and rests not a moment. Quietude is inconceivable to her, and she has laid her curse upon rest. She is firm. Her steps are measured, her exceptions rare, her laws unchangeable.

She has always thought and always thinks; though not as a man, but as Nature. She broods over an allcomprehending idea, which no searching can find out.

Mankind dwell in her and she in them. With all men she plays a game for love, and rejoices the more they win. With many, her moves are so hidden, that the game is over before they know it.

That which is most unnatural is still Nature; the stupidest philistinism has a touch of her genius. Whoso cannot see her everywhere, sees her nowhere rightly.

She loves herself, and her innumerable eyes and affections are fixed upon herself. She has divided herself that she may be her own delight. She causes an endless succession of new capacities for enjoyment to spring up, that her insatiable sympathy may be assuaged.

She rejoices in illusion. Whoso destroys it in himself and others, him she punishes with the sternest tyranny. Whoso follows her in faith, him she takes as a child to her bosom.

Her children are numberless. To none is she altogether miserly; but she has her favourites, on whom she squanders much, and for whom she makes great sacrifices. Over greatness she spreads her shield.

She tosses her creatures out of nothingness, and tells them not whence they came, nor whither they go. It is their business to run, she knows the road. 